CLINICAL STUDY

\title{
Low plasma adiponectin concentration is an indicator of the metabolic syndrome
}

\author{
Merja Santaniemi, Y Antero Kesäniemi and Olavi Ukkola \\ Department of Internal Medicine and Biocenter Oulu, University of Oulu, PO Box 5000, 90014 Oulu, Finland \\ (Correspondence should be addressed to M Santaniemi; Email: merja.santaniemi@oulu.fi)
}

\begin{abstract}
Objective: Adiponectin is an adipocytokine known to be decreased in obesity. It functions in glucose and fatty acid metabolism and also has an anti-inflammatory role in microvasculature. We wanted to investigate the role of adiponectin as a biomarker of metabolic syndrome (MS) and see how the plasma adiponectin levels relate to new criteria of MS proposed by the International Diabetes Federation. Methods: Plasma adiponectin concentrations were measured from total of 1041 Finnish subjects with an ELISA - a novel method planned in our laboratory.

Results: In both the sexes, the plasma adiponectin levels were lower in subjects with MS when compared with subjects with no diagnosis of MS $(P<0.001)$. Plasma adiponectin levels did not differ between subjects with National Cholesterol Education Program (ATPIII) and International Diabetes Federation-defined MS. Lower adiponectin levels were associated with different components of the MS and there was a trend towards decreasing adiponectin levels with an increasing number of components of MS in both the sexes. Subjects in the lowest adiponectin quartile had a significantly higher probability of having MS $(P<0.001), 4$.4-fold in males and 7.5-fold in females, when compared with the corresponding individuals in the highest quartile. The probability increased in every lowering quartile of adiponectin level and was independent of body mass index.

Conclusion: We conclude that adiponectin levels correlate with most of the components of the MS and the metabolic cluster per se.
\end{abstract}

European Journal of Endocrinology 155 745-750

\section{Introduction}

Obesity, in particular visceral adiposity, is known to be associated with insulin resistance and a heterogeneous disorder, metabolic syndrome (MS). The MS is a cluster of interrelated common clinical disorders, including hypertension, insulin resistance, glucose intolerance and dyslipidaemia, in addition to obesity (1). These disorders have cardiovascular consequences and thus obesity can be seen as a major public health issue. The adipokine hypothesis is one of the physiological mechanisms used to explain how excess body fat leads to numerous health consequences. Adiponectin is an adipokine secreted specifically from the adipose tissue. The inverse relationship between body fat and serum adiponectin levels has been demonstrated, and weight reduction can increase adiponectin levels $(2,3)$. Adiponectin modulates glucose metabolism by having insulin-sensitising effects (4-6). Adiponectin also decreases circulating free fatty acid concentrations and muscle triglyceride content by stimulating fatty acid oxidation in muscle via AMP-activated protein kinase (AMPK) $(6,7)$. Thus, adiponectin is a hormone that links adipose tissue and whole-body glucose metabolism. Low adiponectin levels have been associated with type 2 diabetes and insulin resistance $(8,9)$. Adiponectin has been found to have vasoprotective and anti-inflammatory effects and therefore could be viewed as a potential link between MS and its cardiovascular consequences. In the present study, we wanted to investigate the relationship between plasma adiponectin levels and the different components of MS in a large, population-based sample of middle-aged subjects. A special interest was to explore how adiponectin levels relate to the new worldwide definitions of MS proposed by the International Diabetes Federation (IDF).

\section{Subjects and methods}

\section{Subjects}

The subjects are participants of Oulu Project Elucidating the Risk of Atherosclerosis study, which is a populationbased epidemiological study addressing the risk factors and disease end points of atherosclerotic cardiovascular diseases. The study group consisted of 1045 subjects randomly selected from Finnish national population register. The participating study subjects visited the 
research laboratory of the Department of Internal Medicine of the University of Oulu. At this visit, a standardised health questionnaire covering the past medical history, present and former medication use, physical activity, smoking habits, alcohol consumption and family history was administered by two specially trained study nurses. The details of the study have been previously described (10). The study design is crosssectional. The main characteristics of study group are shown in Table 1. Plasma adiponectin level was measured from a total of 1041 subjects.

\section{Clinical measurements}

Laboratory analyses were obtained after an overnight fast and plasma was separated by centrifugation and stored at $-20{ }^{\circ} \mathrm{C}$. The fasting glucose, insulin, lipoprotein fractions, total cholesterol and triglycerides were measured as previously described (14). C-reactive protein was measured with a commercial ELISA kit (Diagnostics Systems Laboratories). Insulin sensitivity was determined by the quick-index $(1 /(\log$ (fasting insulin $)+\log ($ fasting glucose $)))(11) \cdot \gamma$-Glutamyl transpeptidase (GGT) activity was measured using the method according to the European Committee for Clinical Laboratory Standards.

Plasma adiponectin concentrations were measured with an ELISA devised in our laboratory. Monoclonal antihuman adiponectin antibody (R\&D-systems, Cat. MAB10651) was used as a capture antibody and biotinylated monoclonal anti-human adiponectin antibody (R\&D-systems, Cat. BAM1065) was used as a detection antibody. Both antibodies were used in a concentration of $2 \mu \mathrm{g} / \mathrm{ml}$. For the detection of biotinlabelled detection antibody, we used alkaline phosphataselabelled NeutrAvidin diluted in the ratio of 1:18 000 (Pierce Cat. 31 002) and 30\% Lumiphos530 (Lumigen, Cat. P-501). The standard curve from 1.56 to $100 \mathrm{ng} / \mathrm{ml}$ was prepared from human recombinant adiponectin (Biovendor, Cat. RD172023100). Plasma samples were diluted in the ratio of 1:500 and the concentrations were

Table 1 The main characteristics of the study group as means (s.D.) or frequencies (percentages).

\begin{tabular}{lcc}
\hline & Males & Females \\
\hline$n$ & 516 & 516 \\
Age (years) & $50.69(5.99)$ & $51.79(5.95)$ \\
Body mass index $\left(\mathrm{kg} / \mathrm{m}^{2}\right)$ & $27.97(4.22)$ & $27.47(5.05)$ \\
Systolic BP $(\mathrm{mmHg})$ & $152.06(21.36)$ & $144.84(22.06)$ \\
Diastolic BP $(\mathrm{mmHg})$ & $92.57(11.98)$ & $85.56(12.00)$ \\
Total serum cholesterol $(\mathrm{mmol} / \mathrm{l})$ & $5.77(1.05)$ & $5.62(1.06)$ \\
LDL $(\mathrm{mmol} / \mathrm{l})$ & $3.66(0.94)$ & $3.40(0.93)$ \\
HDL $(\mathrm{mmol} / \mathrm{l})$ & $1.20(0.30)$ & $1.49(0.38)$ \\
Triglycerides $(\mathrm{mmol} / \mathrm{l})$ & $1.78(1.08)$ & $1.40(0.94)$ \\
Blood glucose $(\mathrm{mmol} / \mathrm{l})$ & $4.87(1.57)$ & $4.64(1.38)$ \\
Plasma adiponectin $(\mu \mathrm{g} / \mathrm{ml})$ & $13.70(5.60)$ & $17.51(6.34)$ \\
Type 2 diabetics & $n=52(10 \%)$ & $n=41(7.8 \%)$ \\
\hline
\end{tabular}

BP, blood pressure; LDL, low density lipoprotein; HDL, high density lipoprotein. measured in duplicate. The intra-assay variation of method was $13.9 \%$ and the inter-assay variation was $15.9 \%$ before and $6.5 \%$ after correction. Type 2 diabetes was determined according to World Health Organisation criteria. The MS was diagnosed on the basis of new criteria of International Diabetes Federation (12). In short, central obesity was defined as waist circumference $\geq 94 \mathrm{~cm}$ in men and $\geq 80$ in women. An elevated triglyceride level was diagnosed if there was a specific treatment for a lipid abnormality or the level was $\geq 1.7 \mathrm{mmol} / \mathrm{l}$. Reduced high density lipoprotein (HDL) cholesterol level was diagnosed when HDL $<1.03 \mathrm{mmol} / \mathrm{l}$ in males and $\mathrm{HDL}<1.29 \mathrm{mmol} / \mathrm{l}$ in females. Elevated blood pressure was diagnosed when systolic $\mathrm{BP} \geq 130 \mathrm{mmHg}$ or diastolic $\mathrm{BP} \geq 85 \mathrm{mmHg}$ or if there was treatment for hypertension. Elevated fasting plasma glucose (FPG) was diagnosed if $\mathrm{FPG}$ was more than $5.6 \mathrm{mmol} / \mathrm{l}$ or if there was previously diagnosed type 2 diabetes. According to the IDF criteria, MS is present if the subject has central obesity combined with any two of the other components.

ATP III (the third report of the National Cholesterol Education Program (NCEP) expert panel on Detection, Evaluation and Treatment of High Blood Cholesterol in Adults) defines MS (13) as involving three or more of the following: waist circumference $>102 \mathrm{~cm}$ in males and $>$ $88 \mathrm{~cm}$ in females, fasting triglycerides $\geq 1.7 \mathrm{mmol} / \mathrm{l}$, HDL cholesterol $<1.03 \mathrm{mmol} / \mathrm{l}$ in males and $<1.3 \mathrm{mmol} / \mathrm{l}$ in females, blood pressure $\geq 130 / 85 \mathrm{mmHg}$ and fasting glucose $\geq 5.6 \mathrm{mmol} / \mathrm{l}$.

\section{Statistical methods}

Statistical analysis was performed by SPSS version 11.5. The linear regression coefficient between the observed adiponectin concentration and the control sample was statistically significant $\left(R^{2}=4.2 \%, P<0.0005\right)$ permitting the correction of adiponectin measurements for the inter-assay variation using the linear regression analysis. Thus, the adiponectin levels were corrected according to the formula $\mathrm{Xa}=\mathrm{X}-\mathrm{ac}(\mathrm{c}-\mathrm{C})$; where $\mathrm{Xa}$ is the individual's adjusted adiponectin concentration; $X$ is the individual's observed adiponectin concentration; ac is the regression coefficient of the observed adiponectin concentration with the concentration of the control sample; $\mathrm{c}$ is the concentration of adiponectin and $\mathrm{C}$ is the mean value of all the control samples. The inter-assay variation was $15.9 \%$ before and $6.5 \%$ after correction.

Descriptions of study population are given as means and s.D.s. Continuous variables were examined for skewness and curtosis, and insulin, glucose, HDL, cholesterol, triglycerides and quick-index were logarithmically transformed to achieve a normal distribution. Pearson correlation analysis of adiponectin and other continuous variables was applied. Comparisons between groups were calculated by Student's t-test or MannWhitney U-test. ANOVA was used to compare the adiponectin levels between the groups based on the number of components of MS. Adiponectin levels were 
divided into quartiles by keeping mean, +1 s.D. and -1 S.D. as limits. Logistic regression analysis was used to define the odds for MS in adiponectin quartiles using adiponectin quartiles alone as well as using the body mass index (BMI) and age as covariates. A $P$ value of $<0.05$ was considered statistically significant.

\section{Results}

\section{Correlations of adiponectin levels with various parameters of metabolic syndrome}

The mean plasma adiponectin level in the study population was $15.6 \mathrm{mg} / \mathrm{l}$ (s.D. 6.28). The mean level in women was $17.51 \mathrm{mg} / \mathrm{l}$ (s.D. 6.34) and $13.70 \mathrm{mg} / \mathrm{l}$ (s.D. 5.60) in men, with the difference between the sexes being statistically significant $(P=0.009)$. The presence of medication for type 2 diabetes may influence the relationship between plasma adiponectin and fasting glucose or quick-index. Therefore, the correlations were calculated after excluding those patients receiving medication. A total of 18 men (3.4\%) and 13 women $(2.5 \%)$ were excluded. In males, adiponectin levels were negatively and statistically significantly correlated with BMI $\left(R^{2}=-0.187, P<0.001\right)$, waist-to-hip-ratio $\left(R^{2}=-0.180, P<0.001\right)$, fasting insulin $\left(R^{2}=-0.193\right.$, $P<0.001)$ and glucose $\left(R^{2}=-0.089, P=0.046\right)$, triglycerides $\left(R^{2}=-0.226, P<0.001\right)$ and $C$-reactive protein (CRP) $\left(R^{2}=-0.087, P=0.049\right)$. In females, adiponectin levels were negatively and statistically significantly correlated with BMI $\left(R^{2}=-0.240, P=0.03\right)$, waist-tohip-ratio $\left(R^{2}=-0.295, P<0.001\right)$, fasting insulin $\left(R^{2}=-0.301, P<0.001\right)$ and glucose $\left(R^{2}=-0.187\right.$, $P<0.001)$, triglycerides $\left(R^{2}=-0.213, P<0.001\right)$ and CRP $\left(R^{2}=-0.207, P<0.001\right)$. Adiponectin levels correlated positively and statistically significantly with HDL-cholesterol $\left(R^{2}=-0.254, P<0.001\right.$ in males and $R^{2}=-0.295, P<0.001$ in females) and quick-index $\left(R^{2}=-0.192, P<0.001\right.$ in males and $R^{2}=-0.297$, $P<0.001$ in females). We also found adiponectin to be correlated negatively with liver enzymes ALAT $\left(R^{2}=-0.163, P<0.001\right.$ in males and $R^{2}=-0.21$, $P<0.001$ in females $)$ and GGT $\left(R^{2}=-0.091, P=0.038\right.$ in males and $R^{2}=-0.181, P<0.001$ in females).

\section{Adiponectin and IDF-defined components of MS}

There were a total of 388 subjects $(37.6 \%$ of all) with MS defined by IDF in the study population and 308 subjects $(29.8 \%)$ with MS defined by NCEP (ATPIII). A total of 223 (43\% of men) men and 165 (32\% of women) women had MS defined by IDF criteria, whereas $32.1 \%$ of men and $26.9 \%$ of women had MS defined by NCEP (ATPIII). In both the sexes and with both criteria of MS, the plasma adiponectin levels were lower in the subjects with MS compared with those without the syndrome $(P<0.001)$. Plasma adiponectin levels did not differ between the groups with differentially diagnosed MS. Males having MS defined by IDF criteria had the plasma adiponectin of $12.3 \mathrm{mg} / \mathrm{l}$ and those having MS defined by NCEP (ATPIII) $12.1 \mathrm{mg} / \mathrm{l}$. In females, the corresponding values were 14.8 and $14.5 \mathrm{mg} / \mathrm{l}$ respectively.

Adiponectin levels were compared with the different components of the MS defined by IDF. Tables 2 and 3 reveal the mean adiponectin concentrations in relation to the clinical features of the MS. We observed that lower adiponectin levels were associated with most features.

The study subjects were grouped on the basis of how many components of MS based on the IDF definition could be diagnosed. To evaluate the association between the multiplicity of components of MS and the hypoadiponectimia, adiponectin levels were compared between groups (Fig. 1). Adiponectin levels decreased in conjunction with the increase in the number of metabolic abnormalities in both sexes.

Using binary logistic regression, we calculated the odds ratio (OR) of the MS as predicted by adiponectin quartiles. Both males and females were divided into four groups based on their plasma adiponectin levels. The ORs were first defined in unadjusted model using only adiponectin quartiles as covariates. The probability of MS was defined as changes in the odds of the event $(\operatorname{Exp}(\mathrm{B}))$ compared with fourth quartile, which had the lowest probability to have MS (Fig. 2). In both the sexes, the odds of having MS was increased in every lower quartile of adiponectin level and thus the probability of having MS was highest in the first adiponectin quartile. Binary logistic model was further adjusted by age, smoking years, grams of alcohol consumption per day, blood pressure medication and lipid medication. In males, the probability to have MS in the third quartile after adjustments was 1.6 (95\% CI: 0.8-2.9, $P=0.153)$, in the second quartile it was $1.9(95 \%$ CI: $1.0-3.3, P=0.040)$ and in the first quartile it was 3.1 (95\% CI: $1.5-6.3, P=0.002)$ when compared with

Table 2 Adiponectin levels as means (S.D.) in subjects positive to individual component of metabolic syndrome (MS) according to International Diabetes Federation (IDF) criteria and in subjects not having the component of MS in males.

\begin{tabular}{lccc}
\hline & \multicolumn{3}{c}{ Plasma adiponectin (mg/l) } \\
\cline { 2 - 4 } Males & $\begin{array}{c}\text { No IDF-criteria } \\
\text { fulfilled }\end{array}$ & $\begin{array}{c}\text { IDF criteria } \\
\text { fulfilled }\end{array}$ & $\begin{array}{c}\text { Student's } \\
t \text {-test }\end{array}$ \\
\hline Metabolic syndrome & $n=293 ; 14.47$ & $n=233 ; 12.28$ & $P<0.001$ \\
& $(5.5)$ & $(5.4)$ & \\
Waist & $n=201 ; 15.01$ & $n=315 ; 12.86$ & $P<0.001$ \\
& $(5.6)$ & $(5.5)$ & \\
Triglycerides & $n=311 ; 14.5$ & $n=205 ; 12.5$ & $P<0.001$ \\
& $(5.6)$ & $(5.4)$ & \\
HDL & $n=364 ; 14.46$ & $n=152 ; 11.86$ & $P<0.001$ \\
& $(5.7)$ & $(4.8)$ & \\
Systolic blood & $n=45 ; 16.09$ & $n=471 ; 13.46$ & $P=0.003$ \\
pressure & $(5.4)$ & $(5.6)$ & \\
Plasma glucose & $n=387 ; 13.74$ & $n=129 ; 13.56$ & $P=0.455^{\mathrm{a}}$ \\
& $(9.37)$ & $(6.25)$ & \\
\hline
\end{tabular}

${ }^{\mathrm{a} M a n n-W h i t n e y ~ U-t e s t . ~ H D L, ~ h i g h ~ d e n s i t y ~ l i p o p r o t e i n . ~}$ 
Table 3 Adiponectin levels as means (s.D.) in female subjects positive to individual component of MS according to International Diabetes Federation criteria, and in those not having the component of MS.

\begin{tabular}{lccc}
\hline & \multicolumn{3}{c}{ Plasma adiponeonectin (mg/l) } \\
\cline { 2 - 4 } Females & $\begin{array}{c}\text { No IDF-criteria } \\
\text { fulfilled }\end{array}$ & $\begin{array}{c}\text { IDF criteria } \\
\text { fulfilled }\end{array}$ & $\begin{array}{c}\text { Student's } \\
t \text {-test }\end{array}$ \\
\hline Metabolic syndrome & $n=315 ; 18.81$ & $n=165 ; 14.74$ & $P<0.001$ \\
& $(6.3)$ & $(5.6)$ & \\
Waist & $n=233 ; 18.94$ & $n=282 ; 16.27$ & $P<0.001$ \\
Triglycerides & $(6.4)$ & $(6.0)$ & \\
& $n=398 ; 18.32$ & $n=118 ; 14.77$ & $P<0.001$ \\
HDL & $(6.4)$ & $(5.33)$ & \\
Systolic blood & $n=352 ; 18.60$ & $n=164 ; 15.17$ & $P<0.001$ \\
pressure & $(5.4)$ & $(5.13)$ & \\
Plasma glucose & $n=96 ; 18.25$ & $n=420 ; 17.22$ & $P=0.203$ \\
& $(6.2)$ & $(6.4)$ & \\
& $n=420 ; 18.18$ & $n=96 ; 14.57$ & $P<0.001^{\text {a }}$ \\
& $(6.3)$ & $(5.8)$ & \\
\hline
\end{tabular}

${ }^{\mathrm{a} M a n n-W h i t n e y}$ U-test.

the fourth quartile. In females, the probability of having MS in the third quartile after adjustments was $1.5(95 \%$ CI: 0.7-3.3, $P=0.305)$, in the second quartile it was 4.2 (95\% CI: 2.0-8.8, $P<0.001)$ and in the first quartile it was 9.4 (95\% CI: 4.1-21.4, $P<0.001)$ when compared with the fourth quartile.

\section{Discussion}

Hypoadiponectimia has already been associated with the risk of the MS in several populations (14-19). Therefore, measurement of adiponectin levels has been considered as being a useful biomarker or even a target for the management of the MS. However, in most reports, the number of subjects has been rather small, and to our knowledge, there are no studies on the plasma adiponectin levels in relation to MS defined on the basis of the new criteria of IDF. In the present study, we analysed a large population of middle-aged Finnish men and women to find out how plasma adiponectin levels are associated with MS defined on the basis of the new criteria. The study allowed us to consider sexspecific differences in adiponectin levels and their interaction with MS. As expected, the adiponectin levels were higher in women than in men (20). In both the sexes, we found that adiponectin was correlated negatively with measures of body fat, fasting plasma glucose and triglycerides and hs-CRP. A positive correlation was found between adiponectin and quickindex, fasting plasma insulin and HDL-cholesterol. These correlations reflect the role of adiponectin in the modulation of insulin sensitivity and cholesterol metabolism. In agreement with the postulated role of adiponectin in modulating liver function $(21,22)$, we also found the correlations of adiponectin and liver enzymes. In our study, a significant difference was noted in adiponectin levels in both the sexes between subjects with MS and those without MS. Despite the differences in definitions of MS, both NCEP- and IDF-defined subjects had low plasma adiponectin levels and both criteria seem to work similarly in the sense of finding subjects with low adiponectin levels. In the new criteria of MS proposed by the IDF, central obesity is a prerequisite risk factor. The involvement of adiponectin in the waist criteria is not surprising since adiponectin
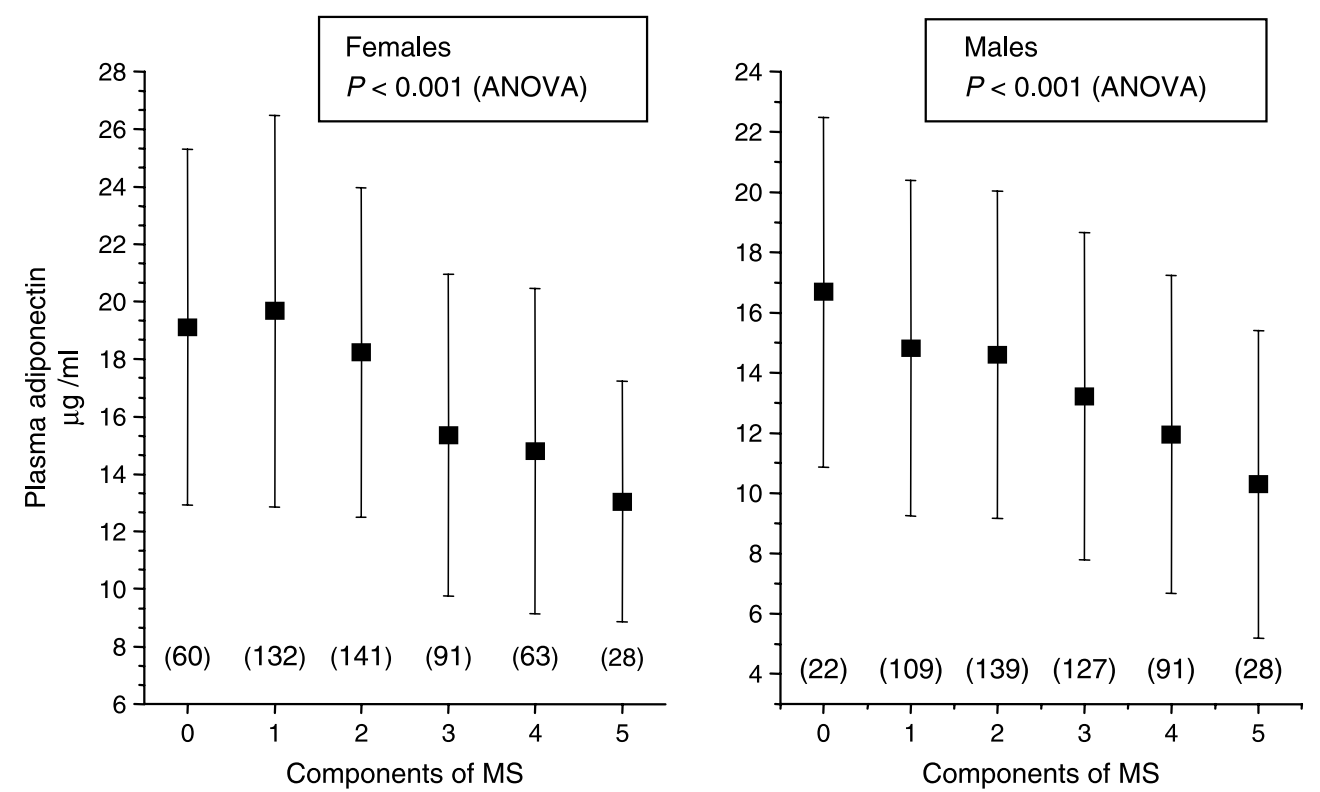

Figure 1 Adiponectin levels according to positive features of MS in females and males. The boxes represent means and the bars represent S.D. The number of subjects is presented in parentheses. 
(a)

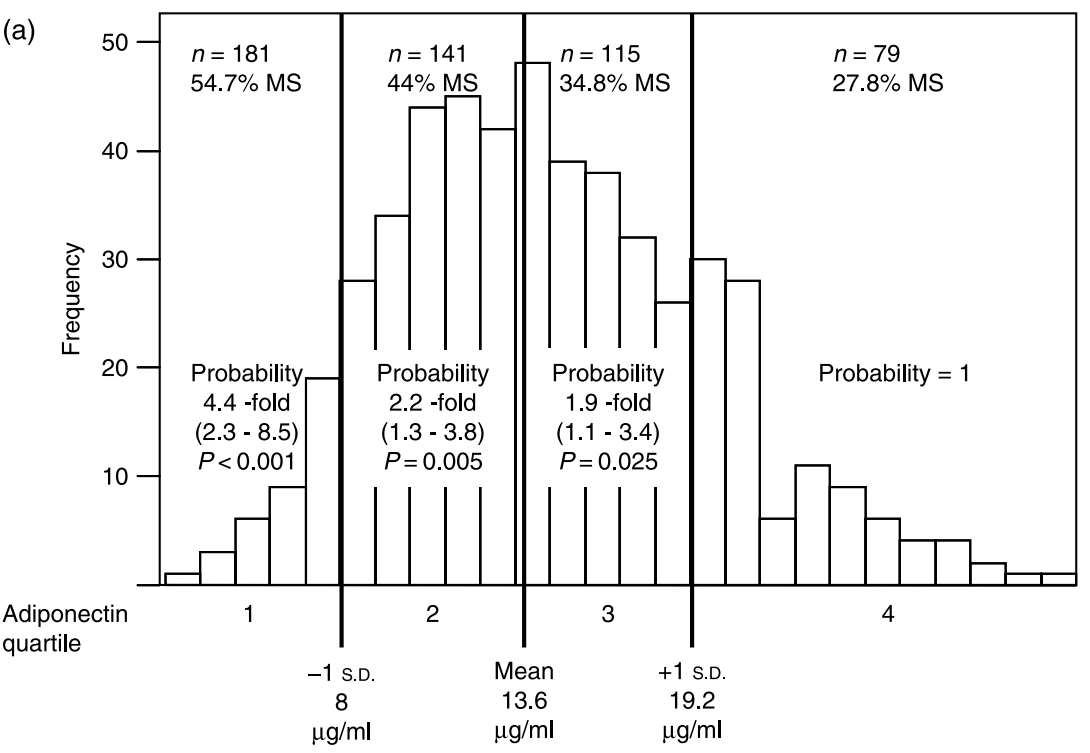

(b)

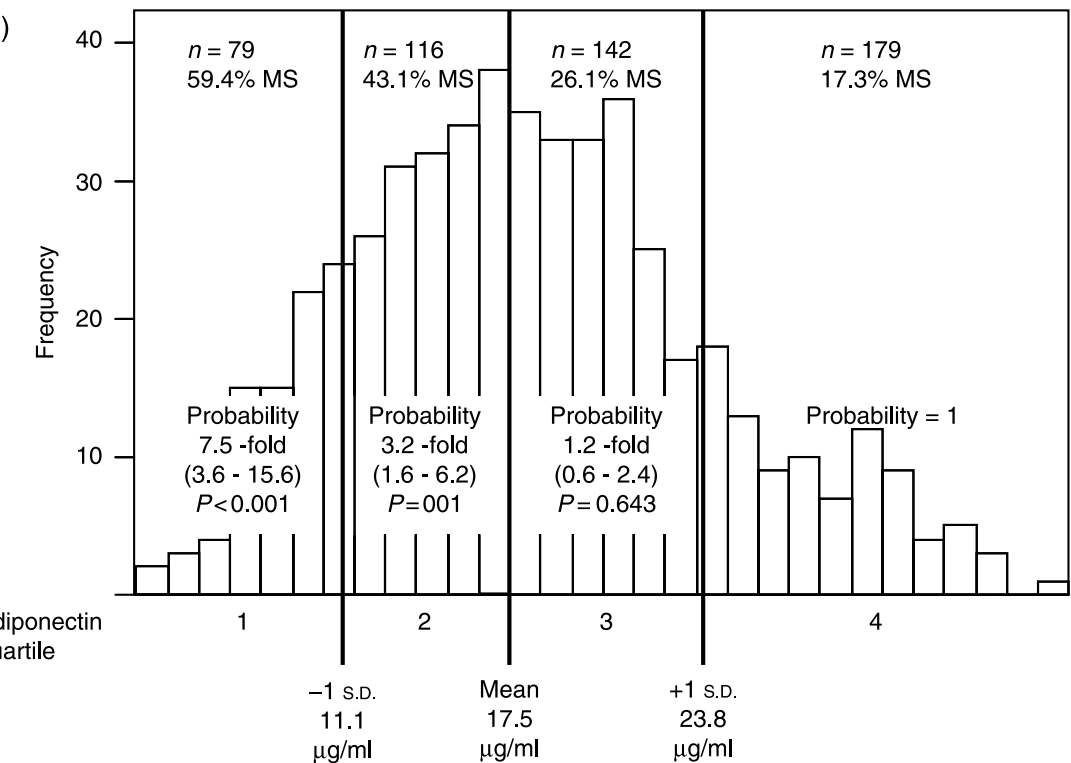

Figure 2 The odds ratio (OR) of the MS as predicted by adiponectin quartiles in (a) males and (b) females in an unadjusted model. The normal distribution of plasma adiponectin levels is shown and the division into quartiles is presented. The probability to have MS is presented as odds ratios (95\% confidence interval) compared with the fourth quartile. At the top of quartile boxes are the numbers of subjects in each quartile and the percentiles of subjects having MS. concentrations are primarily determined by the degree of the visceral fat. In addition, adiponectin seems to have an important role, independent of BMI, on the HDL and the triglyceride levels. According to recent reports $(23,24)$, adiponectin may contribute to the regulation of hepatic lipase activity and represent the link between the insulin-resistant conditions and high plasma triglycerides and low HDL-cholesterol. In support of the latter hypothesis, adiponectin levels were significantly lower, in our study, in those patients with low HDL-cholesterol or high triglyceride levels. Considering the IDF criteria of blood pressure, lower adiponectin levels were seen in both sexes in the group of higher blood pressure, but the difference was statistically significant only in males. Adiponectin levels were lower in female subjects with positive criteria of blood glucose component of MS compared with those not having this component. Our results suggest that in females, low adiponectin levels were even more related to the probability of having MS compared with the role in males (Fig. 2). Interestingly, it has been found that females have higher proportions of high molecular weight and hexameric forms of adiponectin and lower proportions of trimers, and that the higher molecular form adiponectin serves as a precursor pool for activation by metabolic stimuli, such as an increased insulin level (20). Therefore, adiponectin could partly explain the better insulin sensitivity of females and could also be one reason why lower adiponectin levels have more deleterious effects in women. Our study is cross-sectional, which does not allow us to infer causality from our results. For example, we cannot 
conclude whether the decreased adiponectin levels are a cause or a consequence of the metabolic state of high glycaemia, dyslipidaemia or inflammation. The major finding of our study was that in both the sexes, those subjects in the lowest adiponectin quartile exhibited a significantly higher probability of having MS when compared with those in the highest quartile. The probability was found to increase in every lowering quartile of the adiponectin level and was independent of BMI. In conclusion, we suggest that adiponectin is a marker of the MS and a marker of the multiplicity of components of MS according to the new criteria of the IDF.

\section{Acknowledgements}

This study was supported by the Medical Council of the Academy of Finland and the Finnish Foundation for Cardiovascular Research. We acknowledge the excellent technical assistance of Ms Helena Kalliokoski, Ms Saija Kortetjärvi, Ms Sirpa Rannikko and Ms Liisa Mannermaa.

\section{References}

1 Moller DM \& KAufman KD. Metabolic syndrome: a clinical and molecular perspective. Annual Review of Medicine 200556 45-62.

2 Arita Y, Kihara S, Ouchi N, Takahashi M, Maeda K, Miyagawa J, Hotta K, Shimomura I, Nakamura T, Miyaoka K, Kuriyama H, Nishida M, Yamashita S, Okubo K, Matsubara K, Muraguchi M, Ohmoto Y, Funahashi T \& Matsuzawa Y. Paradoxical decrease of an adipose-specific protein adiponectin, in obesity. Biochemical and Biophysical Research Communications 1999257 79-83.

3 Yang WS, Lee WJ, Funahashi T, Tanaka S, Matsuzawa Y, Chao CL, Chen CL, Tai TY \& Chuang LM. Weight reduction increases plasma levels of an adipose-derived anti-inflammatory protein, adiponectin. Clinics in Endocrinology and Metabolism 200186 3815-3819.

4 Berg AH, Combs TP, Du X, Brownlee M \& Scherer PE. The adipocytesecreted protein Acrp30 enhances hepatic insulin action. Nature Medicine 20018 947-953.

5 Yamauchi T, Kamon J, Minokoshi Y, Ito Y, Waki H, Uchida S, Yamashita S, Noda M, Kita S, Ueki K, Eto K, Akanuma Y, Froguel P, Foufelle F, Ferre P, Carling D, Kimura S, Nagai R, Kahn BB \& Kadowaki T. Adiponectin stimulates glucose utilization and fattyacid oxidation by activating AMP-activated protein kinase. Nature Medicine 200211 1288-1295.

$6 \mathrm{Wu} \mathrm{X,} \mathrm{Motoshima} \mathrm{H,} \mathrm{Mahadev} \mathrm{K,} \mathrm{Stalker} \mathrm{TJ,} \mathrm{Scalia} \mathrm{R} \mathrm{\&}$ Goldstein BJ. Involvement of AMP-activated protein kinase in glucose uptake stimulated by the globular domain of adiponectin in primary rat adipocytes. Diabetes 200352 1355-1363.

7 Fruebis J, Tsao TS, Javorschi S, Ebbets-Reed D, Erickson MR, Yen FT, Bihain BE \& Lodish HF. Proteolytic cleavage product of $30-\mathrm{kDa}$ adipocyte complement-related protein increases fatty acid oxidation in muscle and causes weight loss in mice. PNAS 200198 2005-2010.

8 Statnick MA, Beavers LS, Conner LJ, Corominola H, Johnson D, Hammond CD, Rafaeloff-Phail R, Seng T, Suter TM, Sluka JP, Ravussin E, Gadski RA \& Caro JF. Decreased expression of apM1 in omental and subcutaneous adipose tissue of humans with type 2 diabetes. International Journal of Experimental Diabetes Research 20001 81-88.

9 Hotta K, Funahashi T, Arita Y, Takahashi M, Matsuda M, Okamoto Y, Iwahashi H, Kuriyama H, Ouchi N, Maeda K, Nishida M, Kihara S, Sakai N, Nakajima T, Hasegawa K, Muraguchi M, Ohmoto Y, Nakamura T, Yamashita S, Hanafusa T
\& Matsuzawa Y. Plasma concentrations of a novel, adipose-specific protein, adiponectin, in type 2 diabetic patients. Arteriosclerosis, Thrombosis, and Vascular Biology 200020 1595-1599.

10 Rantala AO, Kauma H, Lilja M, Savolainen MJ, Reunanen A \& Kesaniemi YA. Prevalence of the metabolic syndrome in drugtreated hypertensive patients and control subjects. Journal of Internal Medicine 1999245 163-174.

11 Katz A, Nambi SS, Mather K, Baron AD, Follmann DA, Sullivan G \& Quon MJ. Quantitative insulin sensitivity check index: a simple, accurate method for assessing insulin sensitivity in humans. Journal of Clinical Endocrinology and Metabolism 200085 2402-2410.

12 IDF Worldwide Definition of the Metabolic Syndrome, available at www.idf.org.

13 Grundy SM, Cleeman JI, Daniels SR, Donato KA, Eckel RH, Franklin BA, Gordon DJ, Krauss RM, Savage PJ, Smith SC, Spertus JA \& Costa F. Diagnosis and management of the metabolic syndrome. An American heart association/national heart, lung, and blood institute scientific statement. Circulation 2005112 2735-2752.

14 Xydakis AM, Case CC, Jones PH, Hoogeveen RC, Liu MY, Smith EO, Nelson KW \& Ballantyne CM. Adiponectin, inflammation, and the expression of the metabolic syndrome in obese individuals: the impact of rapid weight loss through caloric restriction. Journal of Clinical Endocrinology and Metabolism 200489 2697-2703.

15 Bugianesi E, Pagotto U, Manini R, Vanni E, Gastaldelli A, de Iasio R, Gentilcore E, Natale S, Cassader M, Rizzetto M, Pasquali R \& Marchesini G. Plasma adiponectin in nonalcoholic fatty liver is related to hepatic insulin resistance and hepatic fat content, not to liver disease severity. Journal of Clinical Endocrinology and Metabolism 200590 3498-3504.

16 Salmenniemi U, Ruotsalainen E, Pihlajamaki J, Vauhkonen I, Kainulainen S, Punnonen K, Vanninen E \& Laakso M. Multiple abnormalities in glucose and energy metabolism and coordinated changes in levels of adiponectin, cytokines, and adhesion molecules in subjects with metabolic syndrome. Circulation 2004 $1103842-3848$.

17 Mohan V, Deepa R, Pradeepa R, Vimaleswaran KS, Mohan A, Velmurugan K \& Radha V. Association of low adiponectin levels with the metabolic syndrome - the Chennai Urban Rural Epidemiology Study (CURES-4). Metabolism 2005 54 476-481.

18 Ryo M, Nakamura T, Kihara S, Kumada M, Shibazaki S, Takahashi M, Nagai M, Matsuzawa Y \& Funahashi T. Adiponectin as a biomarker of the metabolic syndrome. Circulation Journal 200468 975-981.

19 Bacha F, Saad R, Gungor N \& Arslanian SA. Adiponectin in youth: relationship to visceral adiposity, insulin sensitivity, and beta-cell function. Diabetes Care 200427 547-552.

20 Peake PW, Kriketos AD, Campbell LV, Shen Y \& Charesworth JA. The metabolism of isoforms of human adiponectin: studies in human subjects and in experimental animals. European Journal of Endocrinology 2005153 409-417.

21 Schulze MB, Rimm EB, Shai I, Rifai N \& Hu FB. Relationship between adiponectin and glycemic control, blood lipids, and inflammatory markers in men with type 2 diabetes. Diabetes Care 200427 1680-1687.

22 Lopez-Bermejo A, Botas P, Funahashi T, Delgado E, Kihara S, Ricart W \& Fernandez-Real JM. Adiponectin, hepatocellular dysfunction and insulin sensitivity. Clinical Endocrinology $200460256-263$.

23 Schneider JG, von Eynatten M, Schiekofer S, Nawroth PP \& Dugi KA. Low plasma adiponectin levels are associated with increased hepatic lipase activity in vivo. Diabetes Care 200528 2181-2186.

24 De Vries R, Wolffenbuttel BH, Sluiter WJ, van Tol A \& Dullaart RP. Post-heparin plasma lipoprotein lipase, but not hepatic lipase activity, is related to plasma adiponectin in type 2 diabetic patients and healthy subjects. Clinical Laboratory $200551403-409$.

Received 27 March 2006

Accepted 31 August 2006 